\title{
Analisis Pengaruh Reliability Sistem Informasi Institusi XYZ Terhadap Kinerja Komisi Berbasis Web
}

\author{
Christy Mahendra ${ }^{* 1}$, Wilson Nasumi Mili ${ }^{2}$, Bergitta Dwi Annawati ${ }^{3}$ \\ ${ }^{1}$ I Program Studi Teknik Informatika, STIKOM Yos Sudarso Purwokerto \\ Jl. SMP 5, Windusara, Karangklesem, Purwokerto Selatan, Banyumas, Jawa Tengah 53144 \\ ${ }^{2}$ Program Studi Sistem Informasi, Universitas Kristen Duta Wacana Yogyakarta \\ Jl. Dr. Wahidin Sudirohusodo No.5-25, Kotabaru, Daerah Istimewa Yogyakarta 55224 \\ ${ }^{3}$ Fakultas Keguruan dan Ilmu Pendidikan Universitas Katolik Widya Mandala Surabaya \\ Jl. Dinoyo No.42-44, Keputran, Tegalsari, Kota Surabaya, Jawa Timur 60265 \\ e-mail:*11 chrisma@ stikomyos.ac.id, ${ }^{2}$ wilson@ staff.ukdw.ac.id, ${ }^{3}$ bergittadwi@ ukwms.ac.id
}

\begin{abstract}
Abstrak
Dalam tata kelola administrasi, institusi XYZ masih mengelola secara manual. Laporan pertanggungjawaban dilaporkan dalam bentuk print out. Pada penelitian ini, institusi XYZ dibangunkan sebuah sistem informasi berbasis web. Penelitian ini menganalisis reliability sistem informasi terhadap perngaruh kinerja komisi. Penelitian ini menggunakan ISO 9001:2008 untuk kuesioner dan perhitungan regresi dalam pengujian sebuah hipotesis. Hipotesis yang ditawarkan sebagai berikut, HO: Tidak ada pengaruh Sistem Informasi XYZ terhadap kinerja dan dalam tata kelola komisi. H1: Ada pengaruh Sistem Informasi XYZ terhadap kinerja dan dalam tata kelola komisi. Untuk mengetahui hipotesis itu berhasil atau tidak, penelitian perlu melihat nilai t table dengan ketentuan $\alpha / 2=0,05 / 2=0,025$, uji sisi karena ingin mengetahui signifikan koefisien regresi.. Jika nilai $t$ hitung $<$ nilai $t$ table, HO diterima. Jika nilai $t$ hitung > nilai t table, HO ditolak. Tes Anova dijadikan dasar untuk mengambil keputusan uji regresi linear sederhana dengan membandingkan nilai signifikan dengan nilai probabilitas 0,05:Jika nilai signifikan < 0,05; artinya variable $x$ berpengaruh terhadap variable y. Berdasarkan nilai t: diketahui nilai thitung sebesar 3,572 > ttabel $=2,048$, sehingga dapat disimpulkan bahwa variable SI $(X)$ berpengaruh terhadap variable Kinerja $(Y)$. Hasil tersebut menjawab hipotesis HI.
\end{abstract}

Kata kunci—Reliability, Regresi, Sistem Informasi, ISO 9001:2008

\begin{abstract}
A In administrative governance, the XYZ institution still manages it manually. The accountability report is reported in print out form. In this research, XYZ institution developed a web-based information system. This study analyzes the reliability of information systems on the influence of commission performance. This study uses ISO 9001: 2008 for questionnaires and regression calculations in testing a hypothesis. The hypothesis offered is as follows, H0: There is no effect of XYZ Information System on performance and in commission governance. H1: There is an influence of the XYZ Information System on performance and on commission governance. To find out whether the hypothesis is successful or not, research needs to look at the t table value with the provisions $\alpha / 2=0.05 / 2=0.025$, side test because you want to know the significant regression coefficient. If the $t$ value $<t$ table value, $\mathrm{HO}$ is accepted. If the value of t count $>$ the value of $t$ table, $\mathrm{HO}$ is rejected. Anova test is used as the basis for making simple linear regression test decisions by comparing the significant value with the probability value of
\end{abstract}


0.05: If the significant value is 60.05 ; this means that the variable $x$ affects the variable $y$. Based on the value of $t$ : it is known that the value of $t$ count is 3.572>t table $=2.048$, so it can be concluded that the variable SI $(X)$ affects the variable Performance $(Y)$. These results answer the hypothesis $H 1$.

Keywords—Reliability, Regression, Information Systems, ISO 9001: 2008

\section{PENDAHULUAN}

$\mathrm{S}$ ebuah institusi semakin terdukung dalam proses pengelolaan data program kerja dengan sebuah perangkat lunak dan teknologi informasi [1]. Sistem informasi manajemen [2] dikembangkan untuk mendukung prosedur pengelolaan transaksi data. Di era digital yang semakin berkembang, konsep manajemen sistem informasi semakin spesifik [3] digunakan seperti teknologi digital, database, web, dan program komputer. Sistem informasi berbasis Web merupakan salah satu media terpopuler [4] dalam menginformasikan produk, kegiatan, dan administrasi sebuah institusi. Melalui Web, pengguna dapat mengakses informasi dimana pun dan kapan pun.

Pada realita di lapangan, sebuah institusi XYZ belum mempunyai format rencana kerja dan format laporan pertanggungjawaban kerja atau dikerjakan secara manual. Sehingga, format rencana kerja dan laporan pertanggungjawaban kerja tidak seragam. Semua rencana kerja dan laporan tidak tertata secara rapih dan benar.

Teknologi informasi digunakan sebagai basis untuk mendukung strategi bisnis perusahaan, meningkatkan kualitas layanan dan proses bisnis [5]. Selama ini, kinerja komisi XYZ mengalami diskontinyuitas. Tidak ada dinamika komisi yang signifikan. Hal ini disebabkan informasi komisi tidak dapat diakses oleh banyak kalangan. Informasi dinamika komisi terbatas pada pelaku komisi. Strategi program komisi tidak mengena kebutuhan banyak orang. Ada banyak komisi tidak membuat program kerja. Kondisi seperti ini menurunkan kualitas pelayanan komisi. Institusi XYZ membutuhkan sistem informasi untuk mendukung strategi dan kinerja. Sistem informasi XYZ berbasis web merupakan sarana manajemen administrasi rencana dan laporan pertanggungjawaban program. Sistem ini dibangun untuk membantu komisi dalam membuat rencana program dan laporan pertanggungjawaban di akhir tahun serta meningkatkan kinerja dinamika komisi.

Pada makalah ini, penulis menganalisis dan mengevaluasi reliability sistem terhadap kinerja komisi. Penulis menganalisis reliability untuk menentukan parameter reliability yang optimal dari komponen sistem [6]. Penulis melakukan sebuah survey untuk mengetahui reliablitiy sistem terhadap kinerja komisi. Penulis menggunakan metode regresi untuk mengolah survey. Analisis komponen utama dan regresi linier dilakukan untuk menguji hipotesis yang disarankan [7]. Penulis membuat sebuah hipotesis penelitian untuk menguji sistem. Sejauh mana sistem berpengaruh bagi kinerja komisi [1].

\section{METODE PENELITIAN}

Penelitian ini bertujuan untuk mendapatkan hasil pengaruh sistem terhadap kinerja. Penelitian ini membawa teknologi visualisasi perangkat lunak lebih dekat dengan praktisi melalui berbagai aplikasi potensial digunakan oleh berbagai pemangku kepentingan perangkat lunak. Sistem ini meliputi persyaratan penelusuran dua arah, fitur (atau konsep) pencarian, pemantauan perkembangan kemajuan, dukungan dari pemikiran desain grup, dan meningkatkan

Christy Mahendra, et., al [Analisis Pengaruh Reliability Sistem Informasi Institusi XYZ Terhadap Kinerja Komisi Berbasis Web] 
komunikasi pemangku kepentingan [8]. Penelitian terbagi menjadi tiga bagian, yaitu kerangka berpikiri, metode penelitian, dan cara kerja.

\subsection{Kerangka Berpikir}

Penulis membuat kerangka berpikir dengan model prototype. Prototype digunakan untuk menghadapi tantangan sistem pelayanan produk [9]. Terdapat lima bagian dalam kerangka berpikir penelitian.

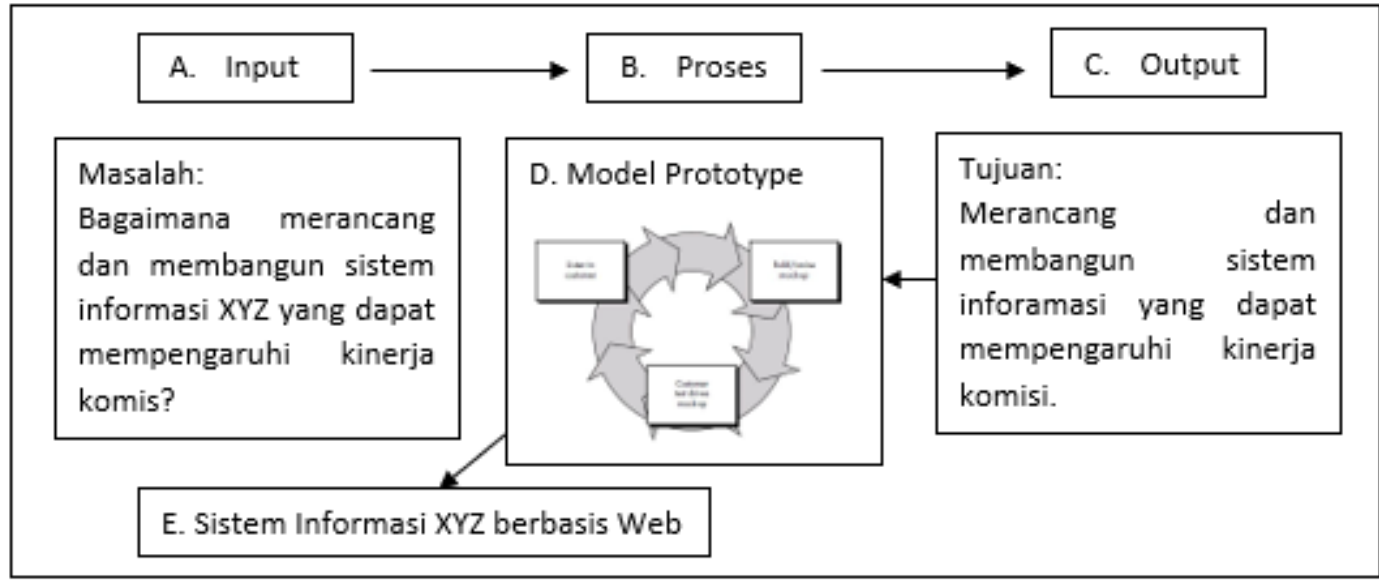

Gambar 1. Kerangka Berpikir Model Prototype

Pada gambar 1 dijelaskan lima bagian kerangka berpikir sebagai berikut:

Tahap A: Input merupakan tahap penginputan data yang terkait dengan masalah yang akan dijawab.

Tahap B: Proses merupakan tahap pengolahan yang akan digunakan untuk memecahkan masalah.

Tahap C: Output yakni hasil dari seluruh rangkaian proses pengolahan dan perancangan sistem.

Tahap D: Model Prototype merupakan metode pendekatan yang digunakan untuk mengolah data yang dimasukan ke dalam sistem.

Tahap E: Outcome yakni hasil akhir dari perancangan sistem yang telah dibuat. Dalam konteks ini, program sudah menjadi sistem yang utuh untuk menyelesaikan masalah yang ada.

\subsection{Metode Penelitian}

Metode penelitian terbagi menjadi tiga, yaitu pendektan penelitian, populasi, prosedur pengembangan instrumen perangkat lunak.

Pendekatan penelitian dilakukan dengan menggunakan menggunakan penelitian survey yang mengkaji populasi dengan menggunakan kuesioner yang akan disebar. Analisis survey yang menggunakan pendekatan kuantitatif memerlukan perencanaan, dan analisis untuk menghasilkan hasil yang dapat mendukung kesimpulan tepat [10].

Populasi dipilih tiga user, yaitu masyarakat XYZ, Ketua Komisi, dan Administrator XYZ. Pemilihan populasi masyarakat XYZ dilakukan secara random dengan mengambil sampling. Dengan populasi random sampling akan mewakili keseimbangan total populasi [11].

Prosedur pengembangan instrumen perangkat dimaksudkan agar peneliti dapat memberikan hasil maksimal dengan langkah yang benar serta menepis kekeliruan yang kecil. Prosedur pengembangan dimaksudkan untuk dokumentasi proses sehingga dapat optimalkan hasil [12]. 


\subsection{Cara Kerja}

\subsubsection{Analisis}

Dalam Rancang Perangkat Lunak, penulis menggunakan cara kerja metode prototype yang terdiri dari:

Pengumpulan kebutuhan dan analisis

Penulis mengumpulkan dokumen-dokumen komisi dan dianalisis sesuai kebutuhan XYZ. Analisis sistem dilakukan dengan melalukan observasi dan wawancara terhadap satuan kerja komisi.

Perancangan cepat

Suatu perancangan perangkat lunak perlu didesain konsep sistem yang akan dirancang. Desain diperoleh berdasarkan hasil analisis yang sudah diperoleh. Langkah pertama yang dibuat oleh perekayasa adalah merancang desain sistem yang akan dibangun dengan Unified Modeling Language (UML). UML merupakan pemodelan proses bisnis yang menjadi kunci rekayasa ulang bisnis [13].

Membangun prototype dengan membuat desain XYZ.

Pada bagian Website akan dibangun hak akses untuk Ketua Komisi dan Administrator

Evaluasi atas prototype program

Prototype yang dirancang awal perlu mendapatkan evaluasi sebagai dasar pengembangan program. Penulis membutuhkan uji coba atas prototype yang sudah jadi. Dalam uji coba tersebut, penulis mengevaluasi kelancaran program saat dijalankan. Penulis menggunaka angket untuk penelitian prototype. Dari hasil angket ini, penulis bisa melihat evaluasi dari user yang akan menggunakan.

Jika prototype kurang puas, maka ada perubahan desain dan kode program untuk dirancang cepat.

Evaluasi menjadi dasar penulis dalam mengadakan pengembangan atau perubahan desain. Harapan dari evaluasi, perubahan dan pengembangan tidak terlalu banyak. Sebab, penulis telah merangcang program melalui UML.

Membangun prototype kembali

Dalam tahap ini, penulis membangun kembali prototype berdasarkan evaluasi yang ada. Prototype yang dibangun kembali menjadi keyakinan penulis maupun pengguna prototype agar sesuai dengan kebutuhan pengguna atas produk ini.

Evaluasi atas prototype program

Evaluasi kedua atas prototype tidak lagi menguji program, tetapi sudah sampai pada evaluasi uji manfaat dan uji kelayakan produk. Evaluasi prototype program mempunyai maksud untuk menyempurnakan produk untuk berpengaruh pada kinerja komisi.

Prototype diterima

Prototype diterima atas persetujuan kedua belah pihak, antara user dan penulis yang membuat produk. Kedua belah pihak harus menyatakan penerimaan sesuai dengan perjanjian kontrak kerja sampai tahap perawatan dan asuransi waktu yang sudah ditentukan.

Pengembangan skala besar

Produk sudah siap digunakan dan disharekan kepada banyak user. Selain dishare, penulis masih bertanggungjawab dalam sosialisasi produk atau pelatihan atas produk kepada pengguna. Setelah itu, produk sudah siap digunakan.

\subsubsection{Evaluasi}

Hipotesis penelitian

Adapun hipotesis penelitian Sistem Informasi XYZ Berbasis Android dan Website berdasarkan pendekatan Regresi sebagai berikut:

Christy Mahendra, et., al [Analisis Pengaruh Reliability Sistem Informasi Institusi XYZ Terhadap Kinerja Komisi Berbasis Web] 
H0: Tidak ada pengaruh Sistem Informasi XYZ terhadap kinerja dan dalam tata kelola administrasi dinamika XYZ yang signifikan.

H1: Ada pengaruh Sistem Informasi XYZ terhadap kinerja dan dalam tata kelola administrasi dinamika XYZ yang signifikan.

Uji normalitas

Untuk mengetahui hipotesis diterima atau hipotesis ditolak, penelitian ini berdasarkan hasil uji Regresi. Untuk menentukan uji Regresi perlu menentukan persamaan regresi dengan rumus:

$$
Y=a+b x
$$

Keterangan:

$\mathrm{Y}=$ kinerja kerja

$\mathrm{a}=$ angka konstan dari Unstandardized Coefisien

$\mathrm{b}=$ angka koefisien regresi

Selanjutnya untuk mengetahui apakah koefisien regresi signifikan atau tidak digunakan uji t untuk menguji signifikan konstanta variable Sistem Informasi Komisi XYZ sebagai predictor untuk variable kinerja untuk membuat hipotesis di atas.

Langkah berikutnya, kita perlu melihat nilai $t$ table dengan ketentuan $\alpha / 2=0,05 / 2=$ 0,025 , uji sisi karena ingin mengetahui signifikan koefisien regresi. Derajat kebebasan (dfdefree of freedom) dihitung dengan rumus $=$ jumlah data -2 .

Selanjutnya, kita menentukan kriteria sebagai dasar pengambil keputusan:

Jika nilai thitung < nilai t table, $\mathrm{H} 0$ diterima

Jika nilai t hitung > nilai t table, $\mathrm{H} 0$ ditolak

Sedangkan pengambil keputusan berdasarkan probabilitas atau signifikan sebagai dasar adalah:

Jika probabilitas (sig.) $>0,025$ (uji dua sisi), H0 diterima

Jika probabilitas (sig.) $<0,025$ (uji dua sisi), H0 ditolak

\subsubsection{Uji Manfaat}

Ada empat tahap dalam menguji manfaat Sistem Informasi XYZ, yaitu:

Menyiapkan Responden

Untuk menentukkan responden random sampling menggunakan rumus

Keterangan:

$$
n=\frac{N}{N . d 2+1}
$$

$\mathrm{N}$ = Jumlah Sampel

$\mathrm{N}=$ Jumlah Populasi

$\mathrm{d} 2=$ Presisi (ditetapkan 10\% dengan tingkat kepercayaan 90\%)

Tabel 1. Sampel Responden

\begin{tabular}{|c|l|c|}
\hline No & Hirarki kelompok pengguna & Jumlah \\
\hline 1 & Ketua Komisi & 5 \\
\hline 2 & Administrator XYZ & 1 \\
\hline 3 & Masyarakat XYZ & 22 \\
\hline 4 & Tim ahli sistem informasi & 2 \\
\hline & Total & 30 \\
\hline
\end{tabular}


Tabel 1 menunjukkan jumlah responden yang akan diminta data melalui kuesioner. Ada empat jenis kelompok responden yang dijadikan sampel dari populasi yang ada, yaitu ketua komisi, administrator XYZ, masyarakat XYZ, dan tim ahli sistem informasi.

\section{Menyiapkan Kuesioner}

Untuk mendapatkan hasil survey atas penelitian ini, penulis menggunakan kuesioner. Kuesioner dibuat untuk meneliti hipotesis. Kuesioner bertujuan untuk mengetahui inisial persepsi pengguna dan harapan dari pengguna [4] terhadap sistem informasi yang akan diuji. Untuk hipotesis berdasarkan Regresi berdasarkan analisis reliability. Analisis reliability menyajikan sistem mekanis berdasarkan kesalahan kinematik dan pendekatan kriging. Kinematik menyangkut akurasi hasil output dan waktu [14]. Adapun jawaban dari responde dikategorikan dalam skala 1-5.

Tabel 2. Skala Nilai

\begin{tabular}{|c|l|l|}
\hline Skala Nilai & \multicolumn{1}{|c|}{ Keterangan } & \multicolumn{1}{c|}{ Skala Likert } \\
\hline 1 & Buruk Sekali (BRS) & $\leq 20 \%$ \\
\hline 2 & Buruk (BR) & $21 \%-\leq 40 \%$ \\
\hline 3 & Sedang (S) & $41 \%-<60 \%$ \\
\hline 4 & Baik (B) & $61 \%-\leq 80 \%$ \\
\hline 5 & Baik Sekali (BS) & $81 \%-\leq 100 \%$ \\
\hline
\end{tabular}

Dalam penilain survey kuesioner yang disebar kepada responden, skala penilaian menggunakan Skala Likert yang terdiri dari lima kategori, yaitu buruk sekali dengan skala < $20 \%$, buruk dengan nilai $21 \%-<40 \%$, sedang dengan nilai $41 \%-<60 \%$, baik dengan nilai $61 \%$ - < 80\%, dan baik sekali dengan nilai $81 \%$ - < 100\%. Skala Likert akan disimbolkan dengan skala nilai 1 sampai dengan 5 seperti yang termuat dalam table 2 .

\subsubsection{Uji Validitas}

Uji validitas ditentukan sebagai kekuatan, kesimpulan, inferensi, atau proposisi dari hasil riset yang sudah penulis lakukan yang mendekati kebenaran. Kesimpulan menurut penulis merupakan suatu skala pengkuran dikatakn valid jika skala tersebut digunakan untuk mengukur apa yang seharusnya diukur yang dihasilkan mendekati kebenaran. Validasi adalah proses penentuan apakah suatu ukuran atau indikator cocok untuk memberikan pengukuran analitis yang berguna untuk tujuan dan konteks tertentu [15].

\subsubsection{Uji Reliabilitas}

Uji Reliabilitas dimaksudkan sebagai adanya konsistensi hasil pengukuran hal yang sama jika dilakukan dalam konteks waktu yang berbeda. Reliabilitas berfokus pada masalah akurasi pengukuran dan hasilnya. Uji reliabilitas merupakan proses penting dalam siklus hidup pengembangan perangkat lunak untuk memastikan keandalan atau kualitas sistem perangkat lunak [16].

Tabel 3. Skala Uji Reliabilitas

\begin{tabular}{|c|l|}
\hline Alpha & \multicolumn{1}{|c|}{ Tingkat Reliabilitas } \\
\hline $0.00-0.20$ & Kurang Reliabel \\
\hline$>0.20-0.40$ & Agak Reliabel \\
\hline$>0.40-0.60$ & Cukup Reliabel \\
\hline$>0.60-0.80$ & Reliabel \\
\hline$>0.80-1.00$ & Sangat Reliabel \\
\hline
\end{tabular}


Reliabilitas sistem untuk pengujian menggunakan skala uji reliabilitas. Skala uji reliabilitas terbagi menjadi lima kategori, yaitu kurang reliabel dengan nilai alpha $0.00-0.20$, agak reliabel dengan nilai alpha $>0.20-0.40$, cukup reliabel dengan nilai alpha $>0.40-0.60$, reliabel dengan nilai alpha $>0.60-0.80$, dan sangat reliabel dengan nilai alpah $>0.80-1.00$.

\section{HASIL DAN PEMBAHASAN}

\subsection{Hasil Uji Nornalitas}

Data yang telah diperoleh akan diuji normalisasi dengan menggunakan metode Kolmogorov-Smirnov. Statistik Kolmogorov-Smirnov adalah salah satu kriteria evaluasi kinerja yang paling penting untuk metode penilaian dan telah banyak digunakan dalam praktek [17]. Metode tersebut digunakan untuk mengetahui untuk mengatahui apakah data tersebut terdistribusi normal atau tidak.

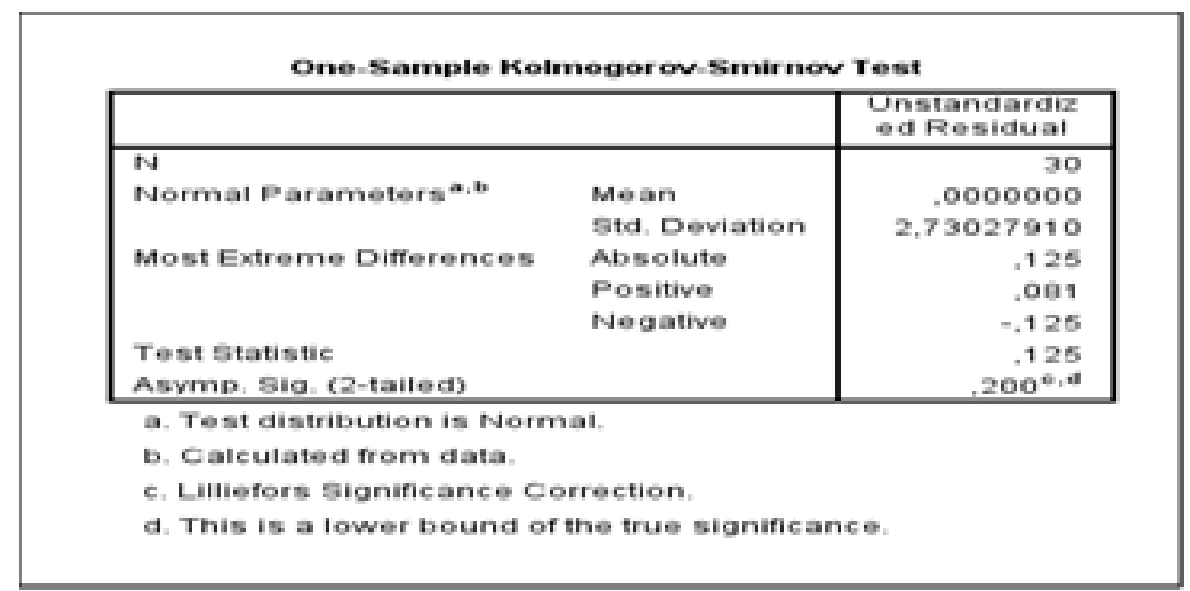

Gambar 2. Hasil Uji Kolmogorov-Smirnov Test

Dari gambar di atas menunjukkan uji normalitas residual 0,200>0,05. Dengan Demikian dapat disimpulkan bahwa nilai residualnya berdistribusi normal.

\subsection{Hasil Uji Hipotesis}

Tes Anova adalah tes standar untuk membandingkan model linear nested yang dipasang oleh kuadrat terkecil [33]. Tes Anova dijadikan dasar untuk mengambil keputusan uji regresi linear sederhana dengan membandingkan nilai signifikan dengan nilai probabilitas 0,05:Jika nilai signifikan $<0,05$; artinya variable $\mathrm{x}$ berpengaruh terhadap variable $\mathrm{y}$.

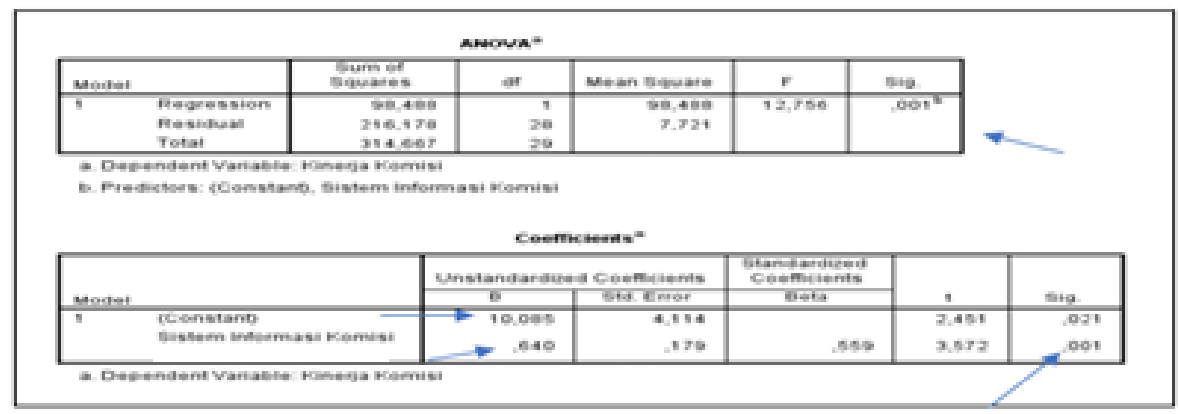

Gambar 3. Regression Anova dan Coefficients 
Jika nilai signifikan > 0,05; artinya variable $\mathrm{x}$ tidak berpengaruh terhadap variable $\mathrm{y}$ $\mathrm{Y}=10,085+0,640 \mathrm{X}$

Nilai sig $=0,001<0,05$ berarti variable SI $(\mathrm{X})$ berpengaruh pada terhadap variable kinerja $(\mathrm{Y})$.

Membandingkan nilai thitung dengan ttabel:

Jika nilai thitung > ttabel; artinya variable $\mathrm{x}$ berpengaruh dengan variable $\mathrm{y}$

Jika nilai thitung < ttabel; artinya variable $\mathrm{x}$ tidak berpengaruh dengan variable $\mathrm{y}$

$$
\text { Ttabel }=(\alpha / 2 ; n-k-1)
$$

Ttabel $=(0,05 / 2 ; 30-1-1)$

$0,025: 28=2,048$

Berdasarkan nilai t: diketahui nilai thitung sebesar 3,572 $>$ ttabel $=2,048$, sehingga dapat disimpulkan bahwa variable SI (X) berpengaruh terhadap variable Kinerja (Y).

Dari perhitungan regresi Anova, variabel $X$ (Sistem Informasi XYZ) mempunyai pengaruh terhadap variabel Y (Kinerja XYZ). Variabel X berisi tentang kemudahan sistem saat dijalankan, keamanan sistem terjaga, sistem dapat efektif digunakan. Sedangkan variabel $\mathrm{Y}$ berisi tentang komisi dapat membuat format program yang sama, komisi dapat membuat kebijakan berdasarkan laporan, pimpinan dapat mengambil keputusan, dan sistem membantu tata kelola administrasi.

\subsection{Hasil Uji Manfaat}

\subsubsection{Hasil Uji Validitas}

Dari hasil analisis tersebut, maka didapatkan nilai dari masing-masing pertanyaan dengan nilai total. Dari gambar di atas, nilai Correlation sebagai berikut: $0.435,0.559,0.475,0.729$, $0.491,0.707,0.569,0.657,0.462,0.814,0.814,0.597$.

Dasar keputusan uji validasi sebagai berikut:

Rhitung $>$ rtabel $=$ valid

Rhitung $<$ rtabel $=$ tidak valid

Rtabel $=\mathrm{N}=30=0.361$

Keputusan uji validitas: semua angket valid

\subsubsection{Hasil Uji Reliabilitas}

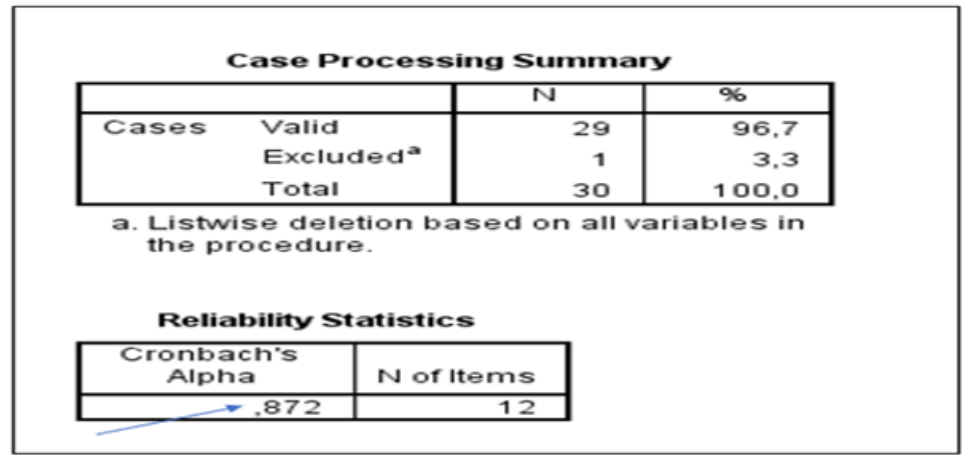

Gambar 4. Hasil Uji Reliabilitas

Dasar keputusan reliability sebagai berikut:

Alpha $>$ rtabel $=$ konsisten

Alpha $<$ rtabel $=$ tidak konsisten

Keputusan uji reliabilitas:

Alpha $=0,872 ;$ Rtabel $=\mathrm{N}=30=0.361$

Maka, semua angket konsisten atau reliablitas.

Christy Mahendra, et., al [Analisis Pengaruh Reliability Sistem Informasi Institusi XYZ Terhadap Kinerja Komisi Berbasis Web] 


\subsection{Intepretasi Hasil}

Dari hasil yang didapatkan dari table 6, maka diketahui persentasi terbesar dalam tiap pertanyaan. Pada table 6 dihasilkan kegunaan Efektif sebesar 100\%, Keterlibatan sebesar 100\%, Manajemen sebesar $100 \%$, dan Keputusan sebesar $100 \%$. Berdasarkan dengan data ini dapat disimpulkan bahwa Sistem Informasi XYZ berpengaruh terhadap dinamika atau kinerja Komisi dan dalam tata kelola administrasi.

Tabel 4 menunjukkan hasil rangkuman uji manfaat dalam bentuk persen. Hasil ini dirangkum dari pengumpulan data kuesioner 30 responden. Dua belas pertanyaan dalam kuesioner dijawab oleh tiga puluh responden, sehingga rata-rata pertanyan terjawab sebanyak 100\%. Kuesioner yang disebar didasari dari ISO 9001:2008 yang berkaitan dengan manajemen. Dari dua belas pertanyaan yang disebar ada empat kategori berkaitan dengan reliabilitas sistem informasi XYZ, yaitu efektifitas sistem (termuat pada pertanyaan P1, P2, dan P3), keterlibatan sistem (termuat pada pertanyaan P4, P5, dan P6), manajemen sistem (termuat pada pertanyaan P7, P10, dan P11), dan keputusan dari sistem (termuat pada pertanyaan (P8 dan P9).

Tabel 4. Rangkuman Hasil Uji Manfaat Dalam \%

\begin{tabular}{|c|c|c|c|c|c|c|c|c|c|c|c|c|}
\hline \multirow[t]{2}{*}{ Kriteria } & \multicolumn{12}{|c|}{ Pertanyaan } \\
\hline & $\mathrm{P} 1$ & $\mathrm{P} 2$ & P3 & $\mathrm{P} 4$ & P5 & P6 & P7 & P8 & $\mathrm{P9}$ & $\mathrm{P} 10$ & $\mathrm{P} 11$ & $\mathrm{P} 12$ \\
\hline \multicolumn{13}{|l|}{ BRS } \\
\hline BR & & 1 & & 1 & 4 & & & & & & & \\
\hline $\mathrm{S}$ & 5 & 11 & 8 & 11 & 17 & 6 & 1 & 8 & 9 & 8 & 8 & 4 \\
\hline B & 17 & 16 & 16 & 12 & 6 & 15 & 7 & 16 & 16 & 13 & 12 & 11 \\
\hline $\mathrm{BS}$ & 8 & 2 & 6 & 6 & 3 & 9 & 22 & 6 & 5 & 9 & 10 & 15 \\
\hline Total & 30 & 30 & 30 & 30 & 30 & 30 & 30 & 30 & 30 & 30 & 30 & 30 \\
\hline \multicolumn{4}{|c|}{ Kegunaan } & \multicolumn{2}{|c|}{ Rata-Rata } & & & & & & & \\
\hline \multicolumn{4}{|c|}{ Efektif (P1, P2, P3) } & \multicolumn{2}{|c|}{$100 \%$} & & & & & & & \\
\hline \multicolumn{4}{|c|}{ Keterlibatan (P4, P5, P6) } & \multicolumn{2}{|c|}{$100 \%$} & & & & & & & \\
\hline \multicolumn{4}{|c|}{ Manajemen (P7, P10,P11) } & \multicolumn{2}{|c|}{$100 \%$} & & & & & & & \\
\hline \multicolumn{4}{|c|}{ Keputusan $(\mathrm{P} 8, \mathrm{P} 9)$} & \multicolumn{2}{|c|}{$100 \%$} & & & & & & & \\
\hline
\end{tabular}

\section{KESIMPULAN}

Berdasarkan hasil penelitian yang telah dilakukan, diperoleh hasil rata-rata kegunaan Efektif sebesar $100 \%$, Keterlibatan sebesar 100\%, Manajemen sebesar 100\%, dan Keputusan sebesar $100 \%$. Penelitian ini menunjukkan uji normalitas residual $0,200>0,05$. Dengan demikian dapat disimpulkan bahwa nilai residualnya berdistribusi normal. Berdasarkan nilai t: diketahui nilai thitung sebesar 3,572 > ttabel $=2,048$, sehingga dapat disimpulkan bahwa variable SI $(\mathrm{X})$ berpengaruh terhadap variable Kinerja $(\mathrm{Y})$.

Dari data tersebut dapat disimpulkan bahwa Sistem Informasi XYZ Berbasis Web Dan Android berpengaruh terhadap dinamika kinerja XYZ dan tata kelola administrasi komisi berdasarkan uji realibility, uji hipotesis, dan uji normalitas. Sistem Informasi XYZ Berbasis Web mempunyai manfaat, antara lain:

Sistem Informasi XYZ membantu Ketua Komisi dalam format tata kelola administrasi pembuatan rencana program komisi dan format laporan pertanggungjawaban komisi. Sistem Informasi XYZ membantu para Ketua Komisi dan Administrator XYZ dalam mendapatkan informasi serta mengambil keputusan atas kritik saran dari umat. Sistem Informasi XYZ membantu umat XYZ dalam mendapatkan informasi komisi secara efektif. 


\section{SARAN}

Saran untuk penelitian selanjutnya adalah pengujian selisih waktu pengerjaan administrasi yang dilakukan secara manual dengan menggunakan sistem informasi XYZ.

\section{UCAPAN TERIMA KASIH}

Penulis mengucapkan terima kasih kepada institusi XYZ yang tidak bisa kami sebutkan nama. Penulis mengucapkan terimakasih karena diberi kesempatan untuk mengembangkan penelitian demi kebaikan institusi dan penulis sendiri.

\section{DAFTAR PUSTAKA}

[1] A. Kock, B. Schulz, J. Kopmann, and H. G. Gemünden. 2020, "Project Portfolio Management Information Systems' Positive Influence on Performance - The Importance of Process Maturity,” Int. J. Proj. Manag., Vol. 38, No. 4, pp. 229-241.

[2] T. Y. Hwang, G. Jung, C. J. Lee, and H. Y. Kim. 2020, "Analysis of Involuntary Admissions in Korea Through The Admission Management Information System," Int. J. Law Psychiatry, Vol. 68, No. July 2019, p. 101542.

[3] S. Y. Eroshkin, N. A. Kameneva, D. V. Kovkov, and A. I. Sukhorukov. 2017, "Conceptual System in The Modern Information Management," Procedia Comput. Sci., Vol. 103, No. October 2016, pp. 609-612.

[4] R. P. Bringula. 2013, "Influence of Faculty- and Web Portal Design-Related Factors On Web Portal Usability: A Hierarchical Regression Analysis," Comput. Educ., Vol. 68, pp. 187-198.

[5] J. S. Suroso and M. A. Fakhrozi, "Assessment of Information System Risk Management with Octave Allegro at Education Institution," in Procedia Computer Science, 2018, Vol. 135, pp. 202-213.

[6] I. Postnikov, V. Stennikov, E. Mednikova, and A. Penkovskii. 2018, "Methodology for Optimization of Component Reliability of Heat Supply Systems, ” Appl. Energy, Vol. 227, No. January, pp. 365-374.

[7] U. Mumtaz, Y. Ali, and A. Petrillo. 2018, "A Linear Regression Approach to Evaluate The Green Supply Chain Management Impact on Industrial Organizational Performance," Sci. Total Environ., Vol. 624, pp. 162-169.

[8] M. Alshakhouri, J. Buchan, and S. G. MacDonell. 2018, "Synchronised Visualisation of Software Process and Product Artefacts: Concept, Design and Prototype Implementation,” Inf. Softw. Technol., Vol. 98, No. January, pp. 131-145.

[9] J. Ilg, C. C. Wuttke, and A. Siefert. 2018, "Systematic Prototyping of Product-Service Systems," Procedia CIRP, Vol. 73, pp. 50-55.

Christy Mahendra, et., al [Analisis Pengaruh Reliability Sistem Informasi Institusi XYZ Terhadap Kinerja Komisi Berbasis Web] 
[10] P. R. Shankar, M. S. Davenport, S. A. Woolen, R. C. Carlos, and K. E. Maturen. 2018, "Survey Research: A Primer for the Academic Radiologist," Acad. Radiol., Vol. 25, No. 6, pp. 751-756.

[11] P. Krabben, J. Nielsen, and M. L. Michelsen. 1997, “Analysis of Single Hyphal Growth And Fragmentation In Submerged Cultures Using A Population Model," Chem. Eng. Sci., Vol. 52, No. 15, pp. 2641-2652.

[12] J. Ray, A. García, A. Manjón, and T. Holt. 2017, "A Review of Basic Procedures for An Organological Examination of Plucked-String Instruments," J. Cult. Herit., Vol. 27, pp. $\mathrm{S} 17-\mathrm{S} 25$.

[13] V. C. Gu, Q. Cao, and W. Duan. 2012, "Unified Modeling Language (UML) IT Adoption - A Holistic Model of Organizational Capabilities Perspective," Decis. Support Syst., Vol. 54, No. 1, pp. 257-269.

[14] L. Wang, X. Zhang, and Y. Zhou. 2018, "An Effective Approach for Kinematic Reliability Analysis of Steering Mechanisms," Reliab. Eng. Syst. Saf., Vol. 180, pp. 6276.

[15] E. A. Frongillo, T. Baranowski, A. F. Subar, J. A. Tooze, and S. I. Kirkpatrick. 2018, "Establishing Validity and Cross-Context Equivalence of Measures and Indicators.," J. Acad. Nutr. Diet., Vol. 0, No. 0, pp. 1-14.

[16] M. R. S. Kaliraj and A. Bharathi. 2018, "Path Testing Based Reliability Analysis Framework of Component Based Software System," Measurement, No. November.

[17] F. Fang and Y. Chen. 2018, "A New Approach for Credit Scoring by Directly Maximizing The Kolmogorov-Smirnov Statistic, ” Comput. Stat. Data Anal. 